Original Article

\title{
EVALUATION OF FREE RADICAL SCAVENGING ABILITY AND ANTIRADICAL ACTIVITIES OF XIMENIA CAFFRA FRUIT EXTRACTS AT DIFFERENT RIPENING STAGES
}

\author{
PENSIA E. MAPUNDA1,2*, COSMAS MLIGO², HERBERT V. M. LYARUU²
}

${ }^{1}$ Department of Conservation Biology, University of Dodoma, Tanzania, ${ }^{2}$ Department of Botany, University of Dar es Salam, Tanzania Email: pensiamapundaa@yahoo.com

Received: 11 Aug 2018 Revised and Accepted: 13 Nov 2018

\begin{abstract}
Objective: To evaluate the free radical scavenging ability and antiradical activities of Ximenia caffra fruit extracts in their different ripening stages.

Methods: Using standard procedures, Ximenia caffra fruit extracts were determined for ferrous ions chelating ability, nitric oxide and hydroxyl radical scavenging ability. Antiradical activities were assessed using 1,1-diphenyl-2-picrylhydrazyl (DPPH) in which the fruit extracts were evaluated for the number of antiradical units $\left(\mathrm{AU}_{515}\right)$, the number of antiradical units per $1 \mathrm{mg}$ of extracts $\left(\mathrm{EAU}_{515}\right)$ and the total number of antiradical units per $1 \mathrm{~g}$ of raw fruits $\left(\mathrm{TAU}_{515}\right)$.

Results: The fruit extracts exhibited significant higher ferrous ion chelating and free radical scavenging capacity compared to synthetic antioxidants (standard). Fruit extracts in early ripening stage (ERS) exhibited stronger ion chelation, nitric oxide and hydroxyl radical scavenging ability with low effective fruit extract concentration required to reduce free radicals by $50 \%\left(\mathrm{EC}_{50}\right)$ that were $14,25 \mathrm{and} 30 \mu \mathrm{g} / \mathrm{ml}$ respectively than the late ripening stage (LRS) extracts. The fruit extracts also showed high $\mathrm{AU}_{515}, \mathrm{EAU}_{515}$ and $\mathrm{TAU}_{515}$. The values of $\mathrm{AU}_{515}$ ranged from 0.93 to 0.95 , while $\mathrm{EAU}_{515}$ from 78.30 to 79.34 and $\mathrm{TAU}_{515}$ ranged from 19762.46 to 23821.23 of the extracts in LRS and ERS respectively.
\end{abstract}

Conclusion: Based on these observations Ximenia caffra is potentially beneficial to human health due to its strong ability to scavenge free radicals. Its utilization can potentially reduce the risk of degenerative diseases to human beings.

Keywords: Antiradical activities, Iron chelation, Radical scavenging, Ripening stages, Ximenia caffra

(c) 2019 The Authors. Published by Innovare Academic Sciences Pvt Ltd. This is an open access article under the CC BY license (http://creativecommons.org/licenses/by/4.0/) DOI: http://dx.doi.org/10.22159/ijpps.2019v11i1.29065

\section{INTRODUCTION}

Free radicals are constantly generated in the human body during the oxidation process. Oxygen is an essential element, particularly in the production of adenosine triphosphate (ATP) which provides energy for cellular functioning. However, during the process several by-products are generated as free radicals [1]. The free radicals have been implicated in many human diseases including accelerated ageing, cancer, cardiovascular diseases, neurodegenerative disease and inflammation. These deleterious effects result from an imbalanced body process of free radicals production and removal that leads to their excessive accumulation such that the bodily defenses fail to prevent oxidative damage [2,3]. Consumption of food rich in antioxidants promotes body defense systems by keeping the amount of the free radicals balanced [4]. However the use of synthetic antioxidants such as butylated hydroxytoluene (BHT) and butylated hydroxyanisole (BHA) that are widely used in the food industry has been associated with harmful effects on human health, like liver damage and carcinogenesis [5, 6]. In consequence, public attention has been focused on natural antioxidants from plant materials as an alternative.

Ximenia caffra is a wild fruit tree of the family Olacaceae native to Tanzania, Kenya, Malawi, Mozambique, South Africa, Uganda and Zambia. It grows in dry woodland and wooded grassland, often on rocky hillsides $[7,8]$. The fruits from the tree are picked and eaten raw after ripening, and refreshing juice can be prepared by squeezing fruits in water and adding sugar $[7,9]$. It has been reported that $X$. caffra has a potential medicinal use by the local communities. The leaves are used as a remedy for malaria, coughs, toothache, stomach-ache, ulcers and hookworm while roots are also used as a cure for infertility, mental illness, bilharzia, scorpion bites, menstrual problems, anaemia, hernia and intestinal worms $[9,10]$. Several studies confirmed that large numbers of medicinal plants are also good free radical scavengers [11-13].

Previous research reported that extracts from leaf and seed of X. caffra have a good number of polyphenol compounds including phenolic acid and flavonoids with strong antioxidant capacity $[9,14]$. Such information is limited in the fruit extracts and this article aimed to unveil the antioxidant potential of $X$. caffra fruits by evaluating their ability to scavenge free radicals and antiradical capacity. The study also determined the optimum fruit phase with a strong antioxidant capacity between the early and late fruit ripening stages. This is because the antioxidant ability is highly correlated with the concentration of phytonutrients that also change with the fruit ripening process [15-17].

\section{MATERIALS AND METHODS}

\section{Chemicals and reagents}

Methanol, ferric chloride, ferrozine, ethylene diamine tetraacetic acid (EDTA) sodium, nitroprusside, sulfanilamide, naphthylethylenediamine dihydrochloride, hydrogen peroxide, potassium phosphate, potassium hydroxide, 1, 1-diphenly-2-picrylhdrazyl (DPPH) ascorbic acid, catechin, and ethyl acetate procured from Sigma-Aldrich Co. (Germany).

\section{Collection and preparation of fruit samples}

Fresh fruits of $X$. Caffra were collected from miombo woodlands of theTunduru District (Latitude: $10.932125{ }^{\circ} \mathrm{N}$ and Longitude: $37.238597^{\circ} \mathrm{E}$ and Altitude: $686 \mathrm{~m}$ ) of Ruvuma Region Tanzania in February 2017. The plant was botanically authenticated by Curator Mr. Frank Mbago of Botany Department Herbarium, University of Dar es Salaam and voucher specimen N0: 20 dated 23/02/2017 was deposited in the Herbarium Department of Botany, University of Dar es Salaam, Tanzania for future reference. Ripe fruits were picked directly from the trees and stored as two different batches. The first batch was for those fruits which were at their early ripening stage (ERS) determined by their bright pink color and second batch were those with deep pink color observed at the late ripening stage (LRS) Samples were then packed in a cooler facility and transported to the Botany Department Laboratory University of Dar es Salaam. In the laboratory, each batch was stored as a dry, pulverized sample and frozen fresh until further analysis. 


\section{Determination of ferrous ion chelating ability}

Ferrous ion chelating ability was determined following the procedure described by Denis TC et al., 1994 [18]. Ten milligrams of fruit extracts were dissolved in $1 \mathrm{ml}$ of distilled water and then 3.7 $\mathrm{ml}$ of methanol and $0.1 \mathrm{mmol}$ ferrous chlorides were added. To initiate the reaction $0.2 \mathrm{ml}$ of $5 \mathrm{mmol}$ ferrozine was also added and the mixture was kept at room temperature for $10 \mathrm{~min}$ before determining the absorbance at $562 \mathrm{~nm}$ against a blank. The effective concentration of the fruit extracts in which ferrous ion was chelated by $50 \%\left(\mathrm{EC}_{50}\right)$ was obtained by plotting the percentage chelation against the concentration of fruit extract. Ethylenediamine tetraacetic acid (EDTA) that was prepared at a concentration similar to that of fruit extracts ( 0.01 to $0.07 \mathrm{mg} / \mathrm{ml})$ was used as a standard.

\section{Nitric oxide radical scavenging activity}

Nitric oxide was determined by generating it from sodium nitroprusside and measured by the Griess reaction as described by Marcoci L et al., 1994 [19]. The procedure is based on the principle that, sodium nitroprusside in aqueous solution at physiological $p \mathrm{H}$ spontaneously generates nitric oxide radicals, which interacts with oxygen to produce nitrite ions that can be estimated by the use of Griess reagent $\left(1 \%\right.$ sulfanilamide, $2 \% \quad \mathrm{H}_{3} \mathrm{PO}_{4}$, and $0.1 \%$ naphthylethylenediamine dihydrochloride). Nitric oxide scavengers compete with oxygen leading to reduced production of nitric oxide radicals. In this study $5 \mathrm{mmol}$ sodium nitroprusside in a standard phosphate buffer solution ( $0.025 \mathrm{mmol}, \mathrm{pH} 7.4)$ was mixed with a different concentration of fruit extracts (0.01-0.07 mg) and incubated at $25^{\circ} \mathrm{C}$ for $60 \mathrm{~min}$. After the incubation time, $0.5 \mathrm{ml}$ of the solution was diluted with $0.5 \mathrm{ml}$ of Griess reagent. The absorbance of the chromophore formed during the diazotization of nitrite with sulfanilamide and its subsequent coupling with naphthylethylenediamine dihydrochloride was read at $546 \mathrm{~nm}$, relative to the absorbance of standard solutions treated in the same way with Greiss reagent. The $\mathrm{EC}_{50}$ was obtained by plotting the percentage nitric oxide radicals reduced against the concentration of fruit sample extract.

\section{Hydroxyl radical scavenging activity}

Hydroxyl radical was determined using deoxyribose sugar, which is degraded by exposure to hydroxyl radicals generated by Fenton reaction $\left(\mathrm{Fe}^{2+}\right.$-ascorbate-EDTA- $\left.\mathrm{H}_{2} \mathrm{O}_{2}\right)$ as described by Halliwell $\mathrm{B}$ et al., 1987 [20]. A mixture (1 ml) contained deoxyribose (2.8 mmol), $\mathrm{KH}_{2} \mathrm{PO}_{4}-\mathrm{KOH}(20 \mathrm{mmol} ; \mathrm{pH} 7.4), \mathrm{FeCl}_{3}$ (100 mmol), EDTA (104 $\mu M), \mathrm{H}_{2} \mathrm{O}_{2}(1 \mathrm{mmol})$ and ascorbate $(100 \mu M)$ were added with different concentration of fruit extracts ranging from 0.01 to $0.07 \mathrm{mg}$ and incubated at $37^{\circ} \mathrm{C}$ for $1 \mathrm{~h}$ to develope a pink chromogen which was measured at $535 \mathrm{~nm}$. Catechin which was prepared at a concentration similar to that of fruit extracts was used as a standard. The $\mathrm{EC}_{50}$ was obtained by plotting the percentage hydroxyl radical reduced against the concentration of extract tested.

\section{Determination of antiradical activity}

Fruit sample for determination of antiradical activity was extracted using three different methods that provide exhaustive extraction of organic compounds as they have different solubility among solvents $[21,22]$. In the first method $(M I)$ samples were extracted using methanol as the first solvent in order to extract a larger quantity of flavonoid and phenolic acid which are soluble in methanol. Five grams of the powdered dry sample was extracted using $200 \mathrm{ml}$ of methanol at $50{ }^{\circ} \mathrm{C}$ for three days. The sample was filtered, and the methanol was evaporated from the filtrate under reduced pressure. The resulted dry residue was dissolved in $50 \mathrm{ml}$ of hot water and stored at $4{ }^{\circ} \mathrm{C}$ for three days. The solution was filtered and the precipitate obtained was marked as sample A $(S A)$ while the remaining solution was extracted five times with $50 \mathrm{ml}$ of ethyl acetate. The resulted solution was then separated by separating funnel, the ethyl acetate extract was evaporated under reduced pressure to obtain an extract marked as sample B $(S B)$ while the remaining aqueous solution was concentrated to dryness under reduced pressure to obtain an extract marked sample $C(S C)$.

In the second method $(M I I)$ a mixture of methanol and water in a ratio of $1: 1$ was the first solvent and it was targeted to include large quantities of tannin in the sample extract because tannin is soluble in a mixture of methanol and water in a ratio of $1: 1$ but is insoluble in methanol. Five grams of fruit powder was treated with $200 \mathrm{ml}$ solution containing methanol and water for two days at $50{ }^{\circ} \mathrm{C}$. Twenty percent of the total volume of the mixture was measured and evaporated under reduced pressure to dryness to obtain an extract marked $S A$. Methanol from the remaining 80 percent of the solution was evaporated under reduced pressure while the resulted aqueous solution was stored at $4{ }^{\circ} \mathrm{C}$ for two days. The solution was filtered and the precipitate was discarded while the filtrate was extracted with ethyl acetate. The solution was then separated as ethyl acetate extract that was further evaporated under reduced pressure to dryness to obtain the extract marked $S B$ while the remaining aqueous solution was concentrated to $S C$.

The third method ( $M I I I)$ was aimed to determine the antiradical activities of fresh fruit juice. In this method, samples were obtained by concentrating the squeezed fruit juice, whereby $200 \mathrm{~g}$ of $X$. caffra fruits were blended to obtain the fruit juice. Then $60 \mathrm{ml}$ of juice was obtained and concentrated to dryness to obtain an extract marked as juice sample $(S)$.

The antiradical activities were measured using stable radical 1, 1diphenly-2-picrylhdrazyl (DPPH), as described by Brand-Williams W et al., 1995 [23]. DPPH has characteristic absorbance at $515 \mathrm{~nm}$ which disappears after its reduction by an antiradical compound. The reduction of DPPH can be monitored using spectrophotometer by measuring the decrease in its absorbance during the reaction. At room temperature, $40 \mu \mathrm{l}$ of fruit sample solution prepared by dissolving the extracted sample in methanol was added to $1460 \mu \mathrm{l}$ of a radical solution prepared by adding $2 \mathrm{mg}$ of DPPH in $54 \mathrm{ml}$ of methanol. The absorbance was then measured at time 0 and after 1 min. The antiradical activities were then calculated as the number of antiradical units $\left(\mathrm{AU}_{515}\right)$, the number of antiradical units per $1 \mathrm{mg}$ of extracts $\left(E A U_{515}\right)$ and the total number of antiradical units per $1 \mathrm{~g}$ of raw fruits ( $\mathrm{TAU}_{515}$ ) according to the equations below.

Percentage yield was calculated for each sample extraction method (I, II and III) according to equation 1.

$$
\mathrm{Y} \%=\frac{\mathrm{Cle}}{\mathrm{W}_{\mathrm{R}}} 100
$$

Equation 1.

Where; $\mathrm{Cle}=$ Total amount of extract $(\mathrm{g})$.

$\mathrm{W}_{\mathrm{R}}=$ Weight of fruit material used for extraction

The antiradical activity unit $\left(\mathrm{AU}_{515}\right)$ was calculated as

$$
\mathrm{AU}_{515}=\left(\mathrm{A}_{0-} \mathrm{A}_{1}\right)-\left(\mathrm{A}_{0 \mathrm{C}}-\mathrm{A}_{1 \mathrm{C}}\right) \quad \text { Equation } 2 .
$$

Where; $\mathrm{AU}_{515}=$ Antiradical activity of the extract,

$\mathrm{A}_{0}=$ Absorbance of the sample at the beginning of the reaction $(0 \mathrm{~min})$,

$A_{1}=$ Absorbance of the sample after 1 min of the reaction,

$\mathrm{A}_{0 \mathrm{C}}=$ Absorbance of the control sample at the beginning of the reaction,

$A_{1 C}=$ Absorbance of the control sample after 1 min of the reaction.

The number of antiradical activity units per $1 \mathrm{mg}$ of each fruit extract $\left(E A U_{515}\right)$ was calculated according to equation 3.

$$
\mathrm{EAU}_{515}=\frac{\mathrm{AU}_{515}}{\mathrm{Ie}} \quad \text { Equation } 3 .
$$

Where; $\mathrm{EAU}_{515}=$ number of antiradical activity per $1 \mathrm{mg}$ of fruit extract,

$\mathrm{AU}_{515}=$ antiradical activity of the extract,

Ie = amount of extract in the sample (mg).

The total number of antiradical activity units (PAU $\left.{ }_{515}\right)$ was calculated separately for each sample extract (SA, SB, SC and $S$ ) according to equation 4 .

$$
\mathrm{PAU}_{515}=\frac{\mathrm{Cle}}{\mathrm{Ie}} \mathrm{AU}_{51}
$$

Equation 4. 
Where; Cle = total amount of extract (mg),

Ie = amount of extract in the sample (mg).

Then the total number of activity unit obtained from $1 \mathrm{~g}$ of raw fruit $\left(\mathrm{TAU}_{515}\right)$ in $M I$ and $M I I$ was calculated as per equation 5.

$$
\mathrm{TAU}_{515}=\frac{\operatorname{PAU}_{515}(A)+\operatorname{PAU}_{515}(B)+\operatorname{PAU}_{515}(C)}{\mathrm{W}_{\mathrm{R}}}
$$

Where; $\operatorname{PAU}_{515}(A)=\operatorname{PAU}_{515}$ calculated from extract $S A$,

$\operatorname{PAU}_{515}(B)=$ PAU $_{515}$ calculated from extract $S B$,

$\operatorname{PAU}_{515}(C)=\mathrm{PAU}_{515}$ calculated from extract $S C$,

$\mathrm{W}_{\mathrm{R}}=$ weight of a fruits taken for sample extraction $(\mathrm{g})$

The total number of activity units (TAU ${ }_{515}$ ) obtained per $1 \mathrm{~g}$ of raw fruits under method M III was calculated as per equation 6 .

$$
\mathrm{TAU}_{515}=\frac{\operatorname{PAU}_{515}(\mathrm{~J})}{\mathrm{W}_{\mathrm{R}}}
$$

Equation 6.

Where; $\mathrm{PAU}_{515}()=\mathrm{PAU}_{515}$ calculated from extract $S J$,

$\mathrm{W}_{\mathrm{R}}=$ weight of fruits used to make juice $(\mathrm{g})$

\section{Statistical analysis}

Statistical analysis was performed using ANOVA. Significant differences between means of extract samples and standards were determined using the Turkey multiple comparison tests as applicable and considered significant when $P<0.05$

\section{RESULTS AND DISCUSSION}

\section{Ferrous ion chelating ability}

Chelating ability of the $X$. caffra fruit extracts increased with concentration (fig. 1). The fruit extract in ERS had shown significant stronger chelating capacity, thereby at a concentration of 0.05 $\mathrm{mg} / \mathrm{ml}$ had $94.61 \%$ than in LRS that had $90.17 \%$ (LSD $=4.447, q=$ 8.262, $P<0.01)$. However, both ERS and LRS extracts showed a stronger chelating capacity than the synthetic metal chelator EDTA $(70.75 \%)$ that was used as standard $(\mathrm{LSD}=23.860, q=44.332$, $P<0.001)$ and $(\mathrm{LSD}=19.413 q=36.070, P<0.001)$ respectively. The $\mathrm{EC}_{50}$ was significantly low $(14 \mu \mathrm{g} / \mathrm{ml})$ in the fruit extract from ERS that signify their strong chelating capacity. While the $\mathrm{EC}_{50}$ from LRS fruit extract and that of EDTA were 17 and $14 \mu \mathrm{g} / \mathrm{ml}$ respectively (F $=555.76, P<0.0001$ ) as shown in table 1 . Ferrous ions are highly reactive and are considered the most effective pro-oxidant among various species of metal ions. It accelerates lipid oxidation by breaking down hydrogen and lipid peroxidase to reactive free radicals through the Fenton reaction [1]. Therefore chelating activity reduces the concentration of the catalyzing transition metal ions in lipid peroxidation and regards as an antioxidant mechanism [24]. The findings of this study showed $X$. caffra fruit extracts can reduce the concentration of metal ions in the human body better than the synthetic metal chelator EDTA and could be an alternate to synthetic antioxidants available in the market that might be healthy unsafe.

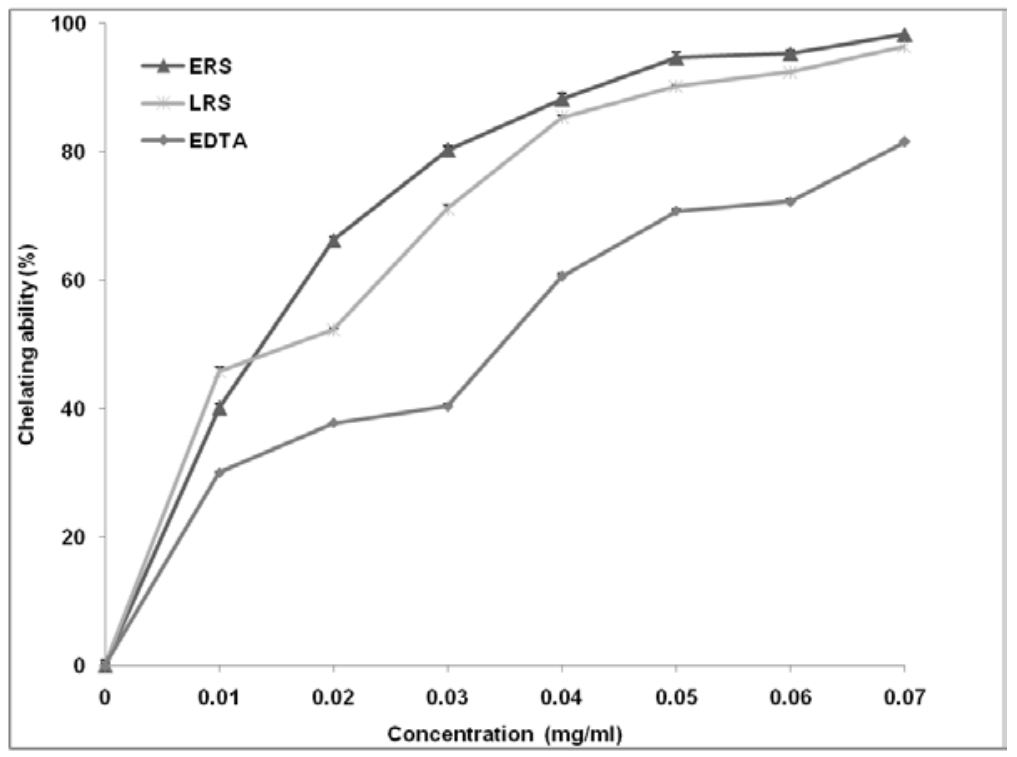

Fig. 1: Ferrous ion chelating ability of $X$. caffra fruit extracts in their early ripening stage (ERS) and late ripening stage (LRS) that were compared with the standard Ethylene diamine tetra acetic acid (EDTA), values are means \pm SE $(n=3)$

\section{Nitric oxide radical scavenging activity}

Ximenia caffra fruit extracts showed a dose-dependent ability on scavenging nitric oxide radical (fig. 2). At $0.04 \mathrm{mg} / \mathrm{ml}$ concentration of dry fruit extracts and ascorbic acid, a synthetic nitric oxide scavenger, ERS showed the highest scavenging ability of $75.21 \%$, followed by extracts from the LRS having $73.16 \%$ and the lowest ability of $30.03 \%$ was recorded in the ascorbic acid. The differences in nitric oxide scavenging ability among fruit extracts and the standard ascorbic acid were statistically significant based on oneway analysis of variance $(\mathrm{F}=978.83, P<0.0001) . \mathrm{EC}_{50}$ of ascorbic acid was achieved at significantly higher concentrations of $50 \mu \mathrm{g} / \mathrm{ml}$ than that of fruit extracts in ERS (LSD $=25.00, q=56.084, P<0.001$ ) and LRS (LSD $=23.000, q=51.598, P<0.00$ ) as shown in table 1 . Although nitric oxide is an essential bioregulatory molecule responsible for a number of physiological processes like neural signal transmission, immune response, vasodilation and control of blood pressure [25], but excessive accumulation may result in several deleterious body conditions such as cancer. Food of plant origin may counteract this effect since they are natural and safe sources of antioxidant than the synthetic antioxidant $[26,27]$. In this study, the extracts of $X$. caffra strongly inhibited the formation of the toxic form of nitric oxide when it was generated from sodium nitroprusside. This finding implies that $X$. caffra fruit had effective nitric oxide scavenging ability and can be used to a significant reduction of nitric oxide harmful effect in the body than the synthesized antioxidant.

\section{Hydroxyl radical scavenging activity}

The ability of $X$. caffra fruit extracts to scavenge hydroxyl radicals was measured by studying competition between deoxyribose and test compounds for hydroxyl radical generated by Fenton reaction. Ximenia caffra fruit extracts showed the strong and concentration dependent capacity of inhibiting deoxyribose oxidation by scavenging the hydroxyl radicals (fig. 3). The fruit extracts in ERS showed a higher 
hydroxyl radical scavenging ability of $80.26 \%$ than in LRS that had $63.75 \%$ and the standard catechin having $42.16 \%$ under $0.05 \mathrm{mg} / \mathrm{ml}$ concentration. Turkey`s test showed that the scavenging ability of the standard catechin was significantly lower than that of fruit extract in ERS (LSD $=38.093, q=45.092, P<0.001$ and LRS (LSD $=21.583, q=$ $25.549, P<0.00)$. The low ability of catechin on hydroxyl radical scavenging was also supported by the recorded higher $\mathrm{EC}_{50}$ value of $57 \mu \mathrm{g} / \mathrm{ml}$ while those of fruit extracts were 30 and $36 \mu \mathrm{g} / \mathrm{ml}$ in ERS and LRS fruit extracts respectively $(\mathrm{F}=904.50, P<0.0001)$. The hydroxyl radical is known as the most powerful radical since it induces severe damage to adjacent bimolecules in the body and its scavenging activity is considered to be one of the most important antioxidant mechanisms in the body [28-30]. Generally, in a concentration range from 0.01 to $0.07 \mathrm{mg} / \mathrm{ml}, X$. caffra fruit extracts had significant stronger scavenging capacity than catechin. These results support that $X$. caffra fruit extracts are better hydroxyl radical scavengers and can potentially reduce the oxidative damage of human body cells.

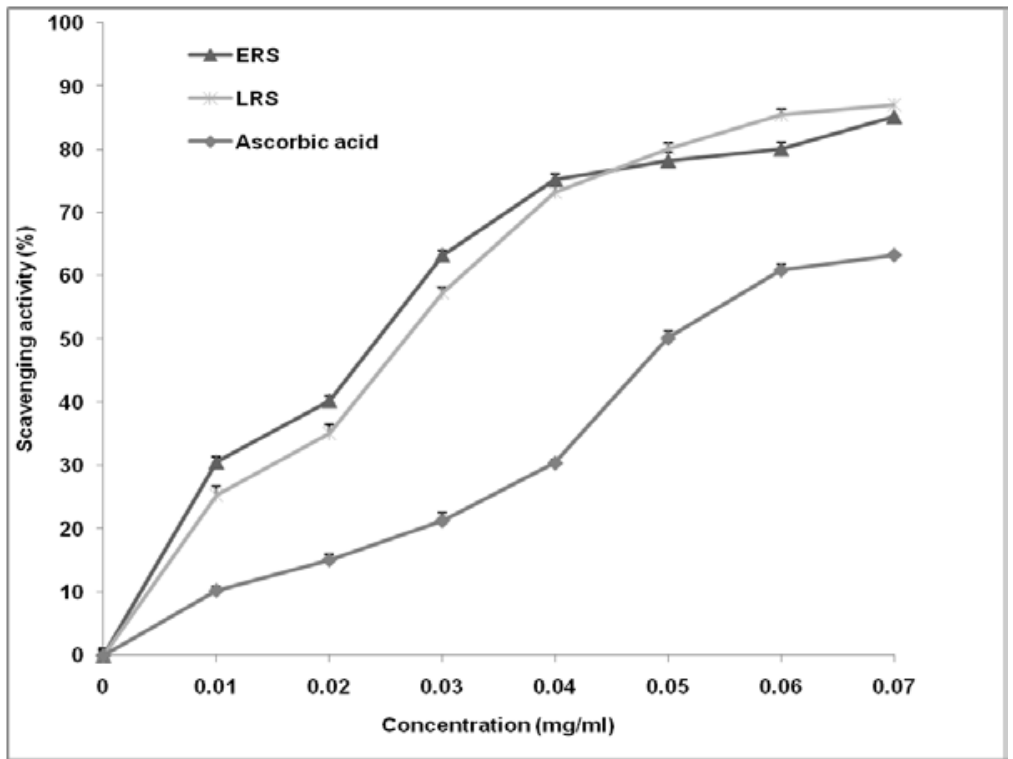

Fig. 2: Nitric oxide radical scavenging activity of $X$. caffra fruit extracts in their early ripening stage (ERS) and late ripening stage (LRS) that were compared with the standard ascorbic acid, values are means $\pm S E(n=3)$

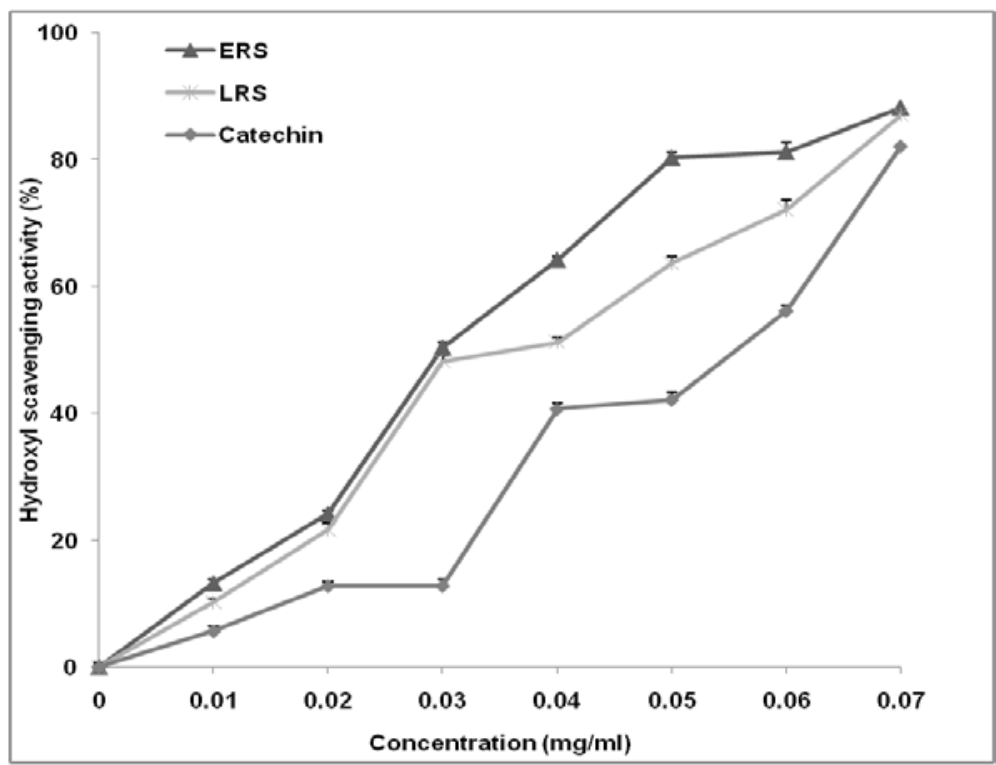

Fig. 3: Hydroxyl radical scavenging activity of $X$. caffra fruit extracts in their early ripening stage (ERS) and late ripening stage (LRS) that were compared with the standard catechin, values are means $\pm S E(n=3)$

Table 1: EC ${ }_{50}$ values of $X$. caffra fruit extracts in their early ripening stage (ERS) and late ripening stage (LRS) with those of standards

\begin{tabular}{llll}
\hline & Iron chelating activity & EC $_{50}(\boldsymbol{\mu g} / \mathbf{m l})$ & OH scavenging activity \\
\hline ERS & NO scavenging activity & $30 \pm 0.5^{\mathrm{a}}$ \\
LRS & $14 \pm 0.6^{\mathrm{a}}$ & $25 \pm 0.6^{\mathrm{a}}$ & $36 \pm 0.6^{\mathrm{b}}$ \\
Standard & $17 \pm 0.4^{\mathrm{b}}$ & $27 \pm 0.1^{\mathrm{b}}$ & $57 \pm 0.3^{\mathrm{c}}$ \\
\hline
\end{tabular}

Values are means $\pm S E(n=3)$. Different letters in superscript indicate significant differences $(P<0.05)$ within the same column 


\section{Antiradical activities}

Antiradical activity characterizes the ability of compounds to react with free radicals in a single reaction [31]. Antiradical activity of $X$. caffra fruit extracts were recorded as $\mathrm{AU}_{515}, \mathrm{EAU}_{515}$, and TAU $\mathrm{U}_{515}$ as summarized in table 2 . The results indicated that different $X$. caffra fruit extracts have strong antiradical activity $\mathrm{AU}_{515}, \mathrm{EAU}_{515}$, and $\mathrm{TAU}_{515}$. The antiradical activity $\mathrm{AU}_{515}$ and EAU $\mathrm{U}_{515}$ were higher in $S J$ fruit extracts followed by $S A, S B$ and lowest activity was found in $S C$ among the extracts. The antiradical activity $\mathrm{TAU}_{515}$ was stronger in the extract obtained using $M I I I$ with activity values ranging from $19762.46 \pm 1.4$ to $23821.32 \pm 2.3$ followed by $M I$ that had $3594.37 \pm 1.93$ to $4828.96 \pm 1.7$, the lowest activity of $1671.60 \pm 1.9$ to $2369.67 \pm 2.7$ was obtained in $M I I$ under LRS and ERS fruit extracts respectively. Extracts from LRS fruits had stronger antiradical activity $\mathrm{AU}_{515}, \mathrm{EAU}_{515}$, and $\mathrm{TAU}_{515}$ compared to that of ERS fruit. This observation could imply a higher concentration of the antiradical exhibiting compound in the LRS compared to the ERS fruits. This is similar to the observation made by Addai ZR et al., 2014 [15] in paw paw, Ding p and Syazwani S 2016 [32] in MD-2 pineapple, Xie G et al., 2016 [17] in wild Rosa laevigata that phenol compounds increase significantly with increasing ripening process. This is because significant physiological, biochemical and structural changes in fruits such as degradation of chlorophylls and synthesis of phytochemical contents occur during the ripening stages [33). This study also revealed that $X$. caffra had strong antiradical activities than most other plant materials reported in the literature. Several studies have reported the presence of higher antiradical activities in different tea species than other plant materials [34-37]. However the quantities reported are lower than those of $X$. caffra observed in this study. Therefore fruits of $X$. caffra should be regarded as a potential source of natural antioxidant and its consumption could be effective in the prevention of oxidative damage. Juice from LRS fruits had strong antiradical activity, hence should be a suitable stage for the harvesting of the fruits so as to obtain the best result based on antiradical capacity.

Table 2: Antiradical activity of $X$. caffra fruit extracts in their early ripening stage (ERS) and late ripening stage (LRS)

\begin{tabular}{|c|c|c|c|c|c|c|c|c|c|}
\hline \multirow[t]{2}{*}{ Methods } & \multirow[t]{2}{*}{ Sample code } & \multicolumn{2}{|l|}{ Yield \% } & \multicolumn{2}{|l|}{$\mathbf{A U}_{515}$} & \multicolumn{2}{|l|}{ EAU $_{515}$} & \multicolumn{2}{|l|}{ TAU $_{515}$} \\
\hline & & ERS & LRS & ERS & LRS & ERS & LRS & ERS & LRS \\
\hline \multirow{4}{*}{$M I$} & $S A$ & $44.86 \pm 0.9$ & $47.57 \pm 0.7$ & $0.66 \pm 0.0$ & $0.83 \pm 0.0$ & $54.81 \pm 0.1$ & $74.96 \pm 0.3$ & & \\
\hline & $S B$ & $4.78 \pm 0.1$ & $3.35 \pm 0.2$ & $0.42 \pm 0.0$ & $0.54 \pm 0.0$ & $35.16 \pm 0.0$ & $44.48 \pm 0.1$ & $3594.37 \pm 1.93$ & $4828.96 \pm 1.7$ \\
\hline & $S C$ & $1.61 \pm 0.0$ & $0.29 \pm 0.1$ & $0.18 \pm 0.0$ & $0.23 \pm 0.0$ & $15.49 \pm 0.0$ & $17.86 \pm 0.0$ & & \\
\hline & $S A$ & $18.42 \pm 0.1$ & $20.47 \pm 0.2$ & $0.73 \pm 0.0$ & $0.91 \pm 0.0$ & $61.22 \pm 0.2$ & $77.59 \pm 0.6$ & & \\
\hline \multirow[t]{2}{*}{ M II } & $S B$ & $1.42 \pm 0.0$ & $1.39 \pm 0.1$ & $0.28 \pm 0.0$ & $0.36 \pm 0.0$ & $23.16 \pm 0.1$ & $30.14 \pm 0.0$ & $1671.60 \pm 1.9$ & $2369.67 \pm 2.7$ \\
\hline & $S C$ & $11.28 \pm 0.0$ & $10.17 \pm 0.1$ & $0.17 \pm 0.0$ & $0.15 \pm 0.0$ & $10.65 \pm 0.3$ & $12.09 \pm 0.1$ & & \\
\hline M III & $S J$ & $4.28 \pm 0.1$ & $5.13 \pm 0.1$ & $0.93 \pm 0.0$ & $0.95 \pm 0.0$ & $78.30 \pm 0.0$ & $79.34 \pm 0.1$ & $19762.46 \pm 1.4$ & $23821.32 \pm 2.3$ \\
\hline
\end{tabular}

Antiradical activity unit ( $\left.\mathrm{AU}_{515}\right)$, total number of antiradical activity unit per $1 \mathrm{mg}$ of extract (EAU 515$)$ obtained in different sample codes $(S A, S B, S C$ and $S J$ ) and total number of antiradical activity unit per $1 \mathrm{~g}$ of raw fruit material (TAU 515 ) calculated in each method of sample extraction (MI, MII, MIII), values are means \pm SE $(n=3)$.

\section{CONCLUSION}

This is the first report on the free radical scavenging ability and antiradical activities in $X$. caffra fruits of Tanzania. The results indicated that X. caffra extracts exhibit excellent antiradical activities and free radical scavenging ability in all assays employed. Extracts from the early stage of fruit ripening are more active radical scavengers while those of the late stage of fruit ripening was more active in antiradical activities. Overall, $X$. caffra fruits are a promising source of natural antioxidants and can be recommended to be included as supplements to human diets so as to minimize cell damage caused by the over-accumulation of free radicals in human bodies.

\section{AUTHORS CONTRIBUTIONS}

Pensia Mapunda designed the experimental study and analysis of the data. Cosmas Mligo and Herbert Lyaruu coordinated manuscript preparation and revision. All authors approved the final version submitted.

\section{CONFLICTS OF INTERESTS}

\section{Declared none}

\section{REFERENCES}

1. Bhattacharya S. Reactive oxygen species and cellular defense system. Free radicals in human health and disease, Springer India, New Delhi; 2015. p. 17-29.

2. Boeing H, Bechthold A, Bub A, Ellinger S, Haller D, Kroke A, et al. Critical review: vegetables and fruit in the prevention of chronic diseases. Eur J Nutr 2012;51:637-63.

3. Sireesha K, Sailaja Rao P. Oxidative stress and diabetes: an overview. Asian J Pharm Clin Res 2015;8:15-9.

4. Gülçin I, Bursal E, Şehitoglu MH, Bilsel M, Goren AC. Polyphenol contents and antioxidant activity of lyophilized aqueous extract of propolis from Erzurum, Turkey. Food Chem Toxicol 2010;48:2227-38.

5. Sun YX, Kennedy JF. Antioxidant activities of different polysaccharide conjugates (CRPs) isolated from the fruiting bodies of Chroogomphis rutilus (Schaeff: Fr.) OK miller. Carbohydr Polym 2010;82:510-4.

6. Vaidya X, Bhati DS, Sharma P, Agnihotri A. Evaluation of phytochemicals and free radical scavenging behavior in different parts of Syzygium cumini. Int J Curr Pharm Res 2017;9:180-5.

7. Ruffo CK, Birnie A, Tengnas BO. Edible wild plants of Tanzania. (Vol 27). Regional Land Management Unit/Sida; 2002.

8. Orwa C, Mutua A, Kindt R, Jamnadass R, Anthony S. Agroforestry tree database: a tree reference and selection guide version 4.0. World Agroforestry Centre ICRAF, Nairobi, KE; 2009.

9. Zhen J, Guo Y, Villani T, Carr S, Brendler T, Mumbengegwi DR, et al. Phytochemical analysis and anti-inflammatory activity of the extracts of the African medicinal plant Ximenia caffra. J Anal Methods Chem 2015;1:1-9.

10. Bruschi P, Morganti M, Mancini M, Signorini MA. Traditional healers and laypeople: a qualitative and quantitative approach to local knowledge on medicinal plants in Muda (Mozambique). J Ethnopharmacol 2011;138:543-63.

11. Ayoub Z, Mehta A. Medicinal plants as potential source of antioxidant agents: a review. Asian J Pharm Clin Res 2018;11:50-6.

12. Maurya SK, Singh AK, Seth A. Potential medicinal plants for lymphatic filariasis: a review. J Crit Rev 2015;2:1-6.

13. Pyo YH, Lee TC, Logendra L, Rosen RT. Antioxidant activity and phenolic compounds of swiss chard (Beta vulgaris subspecies cycla) extracts. Food Chem 2004;85:19-26.

14. Chivandi E. In vitro and in vivo chemical characterization of kigelia africana, mimusops zeyheri, terminalia sericea and ximenia caffra nuts (PhD Thesis) South Africa: University of the Witwatersrand; 2012.

15. Addai ZR, Abdullah A, Mutalib SA. Effect of extraction solvents on the phenolic content and antioxidant properties of two papaya cultivars. J Med Plants Res 2013;7:3354-9.

16. Bhandari SR, Jung BD, Baek HY, Lee YS. Ripening-dependent changes in phytonutrients and antioxidant activity of red pepper (Capsicum annuum L.) fruits cultivated under open-field conditions. Hort Sci 2013;48:1275-82.

17. Xie G, Wang J, Xu X, Wang R, Zhou X, Liu Z. Effect of different ripening stages on bioactive compounds and antioxidant 
capacity of wild Rosa laevigata michx. Food Sci Technol 2016;36:396-400.

18. Dinis TC, Madeira VM, Almeida LM. Action of phenolic derivatives (acetaminophen, salicylate, and 5-aminosalicylate) as inhibitors of membrane lipid peroxidation and as peroxyl radical scavengers. Arch Biochem Biophys 1994;315:161-9.

19. Marcocci L, Maguire JJ, Droy Lefaix MT, Packer L. The nitric oxide-scavenging properties of Ginkgo biloba extract EGb 761. Biochem Biophys Res Commun 1994;15:748-55.

20. Halliwell B, Gutteridge JMC, Aruoma OI. The deoxyribose method: a sample test tube assay for determination of rate constants for reactions of hydroxyl radicals. Anal Biochem 1987;165:215-9.

21. Gao QH, Wu PT, Liu JR, Wu CS, Parry JW, Wang M. Physicochemical properties and antioxidant capacity of different jujube (Ziziphus jujuba Mill.) cultivars grown in loess plateau of China. Sci Hortic 2011;130:67-72.

22. Altemimi A, Lakhssassi N, Baharlouei A, Watson DG, Lightfoot DA. Phytochemicals: extraction, isolation, and identification of bioactive compounds from plant extracts. Plants 2017;6:42.

23. Brand Willium W, Cvelier ME, Berset C. Use of free radical methods to evaluate antiradical activity. Technol Innovation 1995;28:25-30.

24. Qiao D, Ke C, Hu B, Luo J, Ye H, Sun Y, et al. Antioxidant activities of polysaccharides from Hyriopsis cumingii. Carbohydr Polym 2009;78:199-204.

25. Wink DA, Kasprzak KS, Maragos CM, Elespuri RK, Misra M, Dunams TM, et al. DNA deaminating ability and genotoxicity of nitric oxide and its progenitors. Science 1991;254:1001-3.

26. Dragsted LO, Krath B, Ravn Haren G, Vogel UB, Vinggaard AM, Jensen PB, et al. Biological effects of fruit and vegetables. Proc Nutr Soc 2006;65:61-7.
27. Aires A, Fernandes C, Carvalho R, Bennett RN, Saavedra MJ, Rosa EAS. Seasonal effects on bioactive compounds and antioxidant capacity of six economically important brassica vegetables. Molecules 2011;16:6816-32.

28. Yang Y, Sun Y, Yi W, Li Y, Fan C, Xin Z, et al. A review of melatonin as a suitable antioxidant against myocardial ischemia-reperfusion injury and clinical heart diseases. J Pineal Res 2014;57:357-66.

29. Sutar RC, Kasture SB, Kalaichelvan VK. Evaluation of the anticonvulsant activity of leaf extracts of Holoptelea integrifolia (Roxb.) planch. Int J Appl Pharm 2014;6:6-8.

30. Raaman N. Antioxidant activities and phytochemical analysis of methanol extract of leaves of Hygrophila auriculata (Schumach) heine. Int J Curr Pharm Res 2017;7:100-5.

31. Tirzitis G, Bartosz G. Determination of antiradical and antioxidant activity: basic principles and new insights. Act Biochim Pol 2010;57:139-42.

32. Ding $P$, Syazwani S. Physicochemical quality, antioxidant compounds and activity of MD-2 pineapple fruit at five ripening stages. Int Food Res J 2015;23:549-55.

33. Melendez-Martinez AJ, Fraser PD, Bramley PM. Accumulation of health-promoting phytochemicals in wild relatives of tomato and their contribution to in vitro antioxidant activity. Phytochemistry 20107;1:1104-4.

34. Luczaj W, Skrzydlewska E. Antioxidative properties of black tea. Prev Med 2005;40:910-8.

35. Ohmori R, Iwamoto $\mathrm{T}$, Tago $\mathrm{M}$, Takeo $\mathrm{T}$, Unno $\mathrm{T}$, Itakura $\mathrm{H}$, et al. Antioxidant activity of various teas against free radicals and LDL oxidation. Lipids 2005;40:849-53.

36. Sroka Abcdefg Z. The screening analysis of the antiradical activity of some plant extracts. Postepy Hig Med Dosw 2006;60:563-70.

37. Sroka Z, Zbikowska B, Hładyszowski J. The antiradical activity of some selected flavones and flavonols. Experimental and quantum mechanical study. J Mol Model 2015;21:307. 